\title{
ARTÍCULO
}

\section{La atención humanitaria como alternativa viable y eficaz a la detención migratoria: por una política migratoria de retorno centrada en la integración Humanitarian assistance as a viable and effective alternative to immigration
detention: for an integration-centered immigration policy on returns}

\author{
Nacho Hernández Moreno \\ Facultad de Turismo y Relaciones Internacionales, Universidad de Murcia \\ Universidad de Murcia
}

Fecha de recepción 28/06/2021 | De aceptación: 11/10/2021 | De publicación: 23/12/2021

\section{RESUMEN.}

La detención de personas por su situación administrativa responde a una política migratoria coercitiva de protección «frente» al «otro», e ignora la perspectiva de integración y de protección «de» personas que debe regir toda estrategia en este contexto. La mera privación de libertad en ausencia de delito presenta serias dificultades para justificar su proporcionalidad, necesidad y razonabilidad por lo que urge la implementación real de alternativas a la detención. Los programas de atención humanitaria a los que fueron liberadas muchas personas de los CIE durante la pandemia pueden constituir una alternativa sólida, viable y eficaz que favorece la integración social.

\section{PALABRAS CLAVE.}

Detención migratoria; alternativas a la detención; atención humanitaria; integración; centros de internamiento de extranjeros.

\section{ABSTRACT.}

Immigration detention is part of a punitive and security-based migration policy of protection "against" the "other", ignoring the protection "of" the "other" and the integration perspective that should govern any strategy in this context. The sole deprivation of liberty in the absence of a crime presents serious difficulties in justifying its proportionality, necessity, and reasonableness, so it is urgent to implement effective alternatives. The humanitarian reception programs to which many people released from the CIE during the pandemic were transferred can stand as a sustainable, viable and effective alternative to immigration detention that may as well favor their social integration.

KEY WORDS.

Immigration detention; alternatives to detention; humanitarian assistance; integration; immigration detention centers. 
Sumario: 1. Introducción. 2. Una política migratoria obsesionada por el control del desplazamiento humano al servicio de la homogeneidad impuesta del Estado-nación. 2.1. La detención migratoria justificada por las políticas coercitivas de control migratorio. 2.2. La detención migratoria como obstáculo a la integración social de personas. 3. Las alternativas a la detención migratoria: el sistema de acogida como alternativa que favorece la integración. 3.1. ¿Por qué hacen falta alternativas? 3.2. ¿Qué alternativas hay? 3.3. Alternativas existentes no previstas en la normativa de extranjería 3.4. Programas de acogida: ¿una alternativa viable y eficaz? 4. Conclusiones. 5. Bibliografía. 6. Referencias.

\section{Introducción}

La detención de personas migradas por motivo de su situación administrativa es una problemática que ha generado mucha literatura en el ámbito académico y mucho debate y activismo en el contexto de la incidencia política de la sociedad civil en España. Se han señalado las disfuncionalidades de los centros de internamiento de extranjeros («CIE») que han sido reflejadas en numerosos informes y estudios, su grave impacto negativo en las personas detenidas, se ha cuestionado su constitucionalidad y su amparo por el derecho internacional de los derechos humanos, y se ha abogado por su fin a través de la clausura definitiva de los CIE por ser una práctica de vulneración de derechos humanos derivada de la privación de libertad por el simple hecho de carecer de autorización de permanencia o estancia en el territorio. Sin embargo, estos debates y esta necesaria labor de incidencia se han centrado en el cierre de los CIE sin ofrecer alternativas que puedan, mediante el impulso adecuado, lograr el fin definitivo de la detención migratoria.

La normativa de extranjería emplea eufemísticamente el término «internamiento», quizá en un intento de mitigar a través del lenguaje el verdadero impacto de la realidad, que no es otra que la privación de libertad de personas migrantes por motivo de su situación administrativa. Se trata, pues, de una «detención», una detención migratoria, y será este, por lo tanto, el término que se usará a lo largo de este trabajo para abordar esta temática. Efectivamente, es una detención que, como medida coercitiva y punitiva propia del derecho penal empleada en el derecho administrativo, es fuente de problemas en forma de vulneración de derechos de las personas afectadas y genera, asimismo, contradicciones en un Estado cuya política migratoria debe girar, entre otros, en torno al principio de «integración social de los inmigrantes mediante políticas transversales dirigidas a toda la ciudadanía». ${ }^{1}$ Es evidente que la propia detención migratoria, más allá de las características y circunstancias existentes en los CIE, que no juegan

\footnotetext{
${ }^{1}$ Artículo 2bis, letra c, de la Ley Orgánica 4/2000, de 11 de enero, sobre derechos y libertades de los extranjeros en España y su integración social.
} 
a su favor, difícilmente podrá respetar, proteger y realizar los derechos humanos de las personas detenidas, ni tampoco favorecer su integración social.

La detención migratoria es un claro y fundamental obstáculo para la integración de personas, máxime si se tiene en cuenta el bajo porcentaje de personas que son realmente expulsadas del territorio desde los CIE. La mayoría de las personas detenidas son finalmente liberadas, por lo que se trata de personas que han sido privadas de su libertad durante hasta dos meses, en un contexto generador de situaciones de vulnerabilidad y que agrava las ya existentes. Todo ello es contrario a cualquier propósito de integración de personas en una sociedad. Sí, se está hablando de integración social de personas que están inmersas en un procedimiento de expulsión. Esta postura tiene una clara justificación: toda persona sometida a dicho procedimiento administrativo sancionador se halla en territorio español y debe tener acceso a las medidas de integración social oportunas. Además, y como ya se ha mencionado, toda persona en ese contexto tiene una alta probabilidad de no ser finalmente expulsada, por lo que en ese caso permanecerá en España.

Es, pues, el momento de hablar de alternativas a la detención migratoria; medidas o proyectos que pongan fin a la práctica coercitiva y punitiva de detención (recordemos, ante un hecho no delictivo) a través de otras posibilidades que sean respetuosas con los derechos humanos de las personas afectadas y que, como se ha demostrado en la práctica allí donde se han empleado, consiguen una mayor tasa de cumplimiento por parte de las personas sometidas a un procedimiento sancionador de expulsión por una cuestión de confianza en el propio sistema. ${ }^{2}$

Existen programas con fines de integración social que constituyen una buena práctica en el contexto de las políticas migratorias del Estado español como son los sistemas de acogida para personas solicitantes y beneficiarias de protección internacional y del estatuto de apátrida, y los programas de atención humanitaria para personas en situación administrativa irregular recién llegadas a las costas cuya devolución no ha podido realizarse en el plazo legal de 72 horas. No son hoy alternativas contempladas por la normativa como medidas cautelares en el procedimiento administrativo sancionador para asegurar la expulsión del territorio, pero son dos sistemas eficaces de integración de personas sin recursos que se

\footnotetext{
${ }^{2}$ SAMPSON, R., CHEW, V., MITCHELL, G. \& BORWING, L. (2015). There Are Alternatives: A Handbook for Preventing Unnecessary Immigration Detention (Revised). Melbourne: International Coalition Detention, p. IV (Executive Summary); y PILZ, B. \& STEVENS, J. (2020). Case Management: Learnings, Tips and Positive Practices. European Alternatives to Detention Network, p. 5.
} 
hayan en riesgo de exclusión social y que pueden presentar diversas situaciones de vulnerabilidad. Sin embargo, durante la pandemia, muchas personas liberadas de los CIE con el objetivo de vaciar dichos centros de detención migratoria fueron trasladadas a programas de atención humanitaria que, sin ser una alternativa, funcionaron de facto, como una. Esta situación ha dado pie a plantear el debate sobre su viabilidad como una verdadera alternativa a la detención migratoria que, a su vez, favorezca la integración de las personas migrantes que, de otro modo, se hallarían detenidas en un CIE.

El objetivo de este trabajo es abordar la problemática de la integración en una estrategia migratoria en la que prima el control sobre la protección en el marco de los procedimientos de retorno, con el ejemplo paradigmático de la detención migratoria, para a continuación explorar distintas alternativas existentes que garantizan un mayor cumplimiento de derechos humanos (enfocadas en una perspectiva de protección), y, finalmente, examinar cómo el actual sistema de acogida gestionado por el Ministerio de Inclusión, Seguridad Social y Migraciones en colaboración con organizaciones sociales, de forma adaptada, puede ofrecer un recurso efectivo al Estado para lograr sus objetivos en aquel contexto desde una perspectiva basada en derechos humanos y en la integración.

\section{Una política migratoria obsesionada por el control del desplazamiento humano al servicio de la} homogeneidad impuesta del Estado-nación

\subsection{La detención migratoria justificada por las políticas coercitivas de control migratorio}

La política migratoria de la Unión Europea y de España, como su guardián, ${ }^{3}$ se basa en una perspectiva defensiva de contención, coerción, dominación e instrumentalización del «otro». Se trata de una reacción frente a la amenaza percibida de la persona extranjera que se enmarca en el miedo a lo diferente, pero un temor que no impide ni malogra una estrategia que también instrumentaliza el desplazamiento humano y a las personas desplazadas, que son consideradas necesarias como objeto para la economía y el mercado.

Esa obsesión controladora llega hasta el punto de instaurar como norma la privación de libertad durante un periodo de hasta dos meses a personas que no han cometido hecho delictivo alguno: basta con carecer de autorización para hallarse en el territorio. Se trata de un control social que crea una frontera interior

\footnotetext{
${ }^{3}$ BARBERO, I. \& DONADIO, G. (2019). La externalización interna de las fronteras en el control migratorio de la UE. Revista CIDOB d'afers internacionals, 122, p. 159.
} 
que establece una clara diferenciación entre ciudadanos comunitarios y nacionales de terceros países que «pone en entredicho la universalidad de los derechos humanos». ${ }^{4}$ Hablamos, pues, de fronteras, aquellas barreras físicas e imaginarias sobre un espacio físico delimitador de distintas soberanías. La frontera es un instrumento útil y necesario para dotar al Estado-nación de su propio sentido como sujeto soberano de un territorio concreto. El territorio es una poderosa herramienta geográfica de control de personas y de los elementos a través del control del espacio en el que se encuentran, por lo que su delimitación fronteriza y el control de su acceso es esencial para lograr dicho fin. ${ }^{5}$ Esta soberanía tiene, por lo tanto, una vertiente física o territorial delimitada por esas barreras, pero también tiene una de tipo personal, cuyo límite es la nacionalidad, entendida como vínculo entre el Estado y la persona a la que considera nacional suyo y, por ende, sometida a su poder y soberanía. De esto se desprende claramente la diferenciación entre nacionales y no nacionales, ${ }^{6}$ entre quienes se hallan dentro o fuera del territorio, pero también entre quienes, encontrándose en el territorio, se hallan dentro o fuera del mundo de la protección y garantía de todos los derechos de la ciudadanía.

El Estado-nación se fue construyendo a través de un proceso de homogeneización agresivo con las diferencias internas y entusiasta de la separación externa, es decir, con respecto a otras comunidades, y favorecedor de una supuesta unidad e identidad común entre los nacionales; la creación simbólica de un endogrupo claramente diferenciado de «otros» (exogrupos) era fundamental para la supervivencia y prosperidad del proyecto de soberanía nacional postwestfaliano. Se trata de forjar una identidad basada en la separación con respecto al «otro» más que en encontrar espacios comunes de convivencia y coexistencia entre quienes habitan un mismo lugar. Surge así un modelo de ciudadanía esquizofrénico en el que cualquier diferencia o distinción de la norma cultural o lingüística se castiga, ${ }^{7}$ ¿y quién mejor que la persona extranjera para encarnar ese «otro» que amenaza esa supuesta homogeneidad nacional? ${ }^{8}$

\footnotetext{
${ }^{4}$ BARONE, S. (2015). Los centros de internamiento de extranjeros (CIEs) entre control migratorio y control social: una frontera interna y polimorfa. Revista de Dialectología y Tradiciones Populares, 70(2), p. 327.

${ }^{5}$ SACK, R. D. (1986). Human Territoriality: Its theory and history. Cambridge: Cambridge University Press, pp. 5, 26 y 27.

${ }^{6}$ Esta idea clásica puede hacerse hoy extensible a la diferenciación entre nacionales y ciudadanos comunitarios, por un lado, y nacionales de terceros países, por el otro. La Unión Europea ha dado pie a que la dicotomía entre personas nacionales y no nacionales se adapte a una nueva realidad en la que se enfrentan, por una parte, las personas nacionales de los Estados miembros de la UE como ciudadanas comunitarias, $\mathrm{y}$, por otra parte, las personas nacionales de terceros países como categoría de persona extranjera con un catálogo menor y reducido de derechos.
}

${ }^{7}$ SUÁREZ NAVAZ, L. (2005). Ciudadanía y Migración: ¿un oxímoron? Puntos de Vista, 4, p. 32.

${ }^{8}$ BAUMAN, Z. (2007). Tiempos líquidos. Vivir en una época de incertidumbre. Barcelona: Tusquets, p. 122. 
En este punto, la idea de favoritismo endogrupal de la teoría de la identidad social de Tajfel y Turner ejerce una oportuna sinergia con el objetivo homogeneizador del Estado-nación, el cual pone su foco en una cultura común mediante la defensa e imposición de una cultura pura, única y propia que puede verse afectada por el contacto con miembros de un exogrupo. Esta combinación facilita su deshumanización, y permite justificar su exclusión sobre la base de la necesidad de mantener una distintividad propia que fomente una identidad social positiva en el endogrupo. ${ }^{9}$

Ha sido recientemente cuando se ha visibilizado de forma drástica el mito de la homogeneidad, pero cuya consecuencia ha sido dar espacio a otra forma de esencialismo en forma de guerra de identidades y culturas que ha motivado un discurso securitario hacia el exterior. La persona extranjera, como decíamos, como persona extraña, ese «otro» que forma parte de un exogrupo y, por lo tanto, contrario al endogrupo y a sus intereses y a todo lo que sus integrantes pueden compartir, es peligrosa y cualquier medida político-militar estará justificada en el nombre de la salvaguarda del endogrupo nacional. Se cierran así las fronteras frente al extraño como chivo expiatorio renovable presentado como «fuente permanente de inquietud e imprevisibilidad que hace inaplazable la función protectora del Estado». ${ }^{10}$ Así, el discurso sobre la inmigración irregular sigue la retórica de una connotación de ilegalidad, prohibición y peligro derivada de la representación de las personas desplazadas como amenaza al orden público y vinculadas a circunstancias como la delincuencia, criminalidad, terrorismo o narcotráfico, lo cual justifica ante la sociedad de acogida el establecimiento de mecanismos excepcionales de control social, entre las que se incluyen los CIE como «cárceles para migrantes». ${ }^{11}$

La Unión Europea es hoy una fortaleza que se presenta con un deseo irrefrenable de ser inexpugnable. Mezcla una retórica de protección de personas y de respeto de los derechos humanos con prácticas de imposible encaje con ese discurso garantista. Prueba de ello es la debatida y actual externalización de fronteras que supone una verdadera externalización de las obligaciones de los Estados miembros en materia de derechos humanos, que son trasladadas a terceros Estados que pueden o no estar vinculados por el derecho internacional de los derechos humanos pero que, a buen seguro, no están obligados por

\footnotetext{
${ }_{9}^{9}$ SWANN, W. B. \& BOSSON, J. K. (2010). Self and Identity. En FISKE, S. T., GILBERT, D. T. \& LINDZEY, G. (eds.), Handbook of Social Psychology, Volume I (págs. 589-628). Princeton: Wiley, p. 611.

${ }^{10}$ SOLANES CORELLA, Á. (2016). Una reflexión iusfilosófica y política sobre las fronteras. Anuario de Filosofia del Derecho, 32, p. 154.

${ }^{11}$ DE LUCAS, J., JARRÍN MORÁN, A. \& RODRÍGUEZ GARCÍA, D. (2012). Los Centros de Internamiento para Extranjeros en España: una evaluación crítica. Revista CIDOB d'afers internacionals, 99, pp. 214-215.
} 
tratados fundamentales en esta materia como la Convenio Europeo de Derechos Humanos. Esta fortaleza simbólica se ha trasladado a la práctica en forma de vallas en las zonas limítrofes y prácticas, como los rechazos en frontera, que sellan el territorio frente a los indeseados, sin distinción entre potenciales personas refugiadas y los mal llamados inmigrantes económicos que, a menudo, esconden también una historia de persecución o maltrato; y se ha hecho también en el interior protegido por esas fronteras a través de la detención migratoria en los CIE como respuesta a la migración irregular amparada por la Unión Europea a través de la Directiva 2008/115/CE, relativa a normas y procedimientos comunes en los Estados miembros para el retorno de los nacionales de terceros países en situación irregular, comúnmente conocida como Directiva de retorno, y también llamada Directiva de la vergüenza.

Es precisamente esa perspectiva de control y contención reactiva frente a una amenaza ilusoria la que justifica un estado de excepción con respecto a las personas en situación administrativa irregular que permite su vulneración de derechos humanos a través de la práctica de la detención en un CIE, socavando así los esfuerzos protectores y garantistas del proyecto europeo. Más allá de las deplorables condiciones de estos centros denunciadas por la sociedad civil y el Defensor del Pueblo en reiteradas ocasiones, la detención en sí misma es una violación del derecho humano a la libertad que no está justificada por no tratarse de una sanción frente a un delito, sino que se trata de una medida punitiva y coercitiva frente al solo hecho de ser una persona que carece de nacionalidad española y a quien el Estado no permite su presencia en su territorio. Nos encontramos ante la problemática de que, además, ese mismo Estado, España en este caso, es productor de irregularidad a través de sus políticas y normativa de extranjería, ${ }^{12}$ no solo por no favorecer vías seguras, ordenadas y regulares tal y como exige el Pacto Mundial de Migraciones adoptado en 2018 y apoyado por España desde sus inicios, sino por generar situaciones de irregularidad sobrevenida, una cuestión claramente reversible. ${ }^{13}$

Esta mirada cortoplacista y defensiva frente a la migración ${ }^{14}$ y este énfasis por la dominación del «otro» ha aumentado los espacios de control de una política selectiva que acaba expulsando a los indeseados y deteniéndolos para asegurar dicho cometido, ${ }^{15}$ que se traslada incluso al ámbito de la protección

\footnotetext{
${ }^{12}$ Ídem, p. 209.

${ }^{13}$ BARONE, S. (2015). Op. cit., p. 328.

${ }^{14}$ GABRIELLI, L. (2017). La externalización europea del control migratorio. ¿La acción española como modelo? Anuario CIDOB de la Inmigración 2017, p. 144.

15 LÓPEZ-SALA, A. \& GODENAU, D. (Coords.) (2017). Estados de contención, Estados de detención. El control de la inmigración irregular en España. Barcelona: Anthropos, p. 17.
} 
internacional, en el que España se presenta ante la comunidad internacional como el Estado con la tasa de reconocimiento más baja de toda la Unión Europea (3,5\% en 2020), por debajo de países como Letonia (4,1\%), la República Checa (4,2\%), Bulgaria (4,8\%), Eslovaquia (6,3\%), Polonia (6,8\%) o Hungría $(17,9 \%) \mathrm{y}$, por supuesto, muy por debajo de la media comunitaria $(20 \%){ }^{16}$

\subsection{La detención migratoria como obstáculo a la integración social de personas}

La detención migratoria en España es un fenómeno relativamente reciente que coincide con la transformación paulatina de un Estado español que había sido testigo del éxodo de millones de nacionales que emigraron fuera de sus fronteras a un país receptor de inmigrantes. Fue la Ley Orgánica 7/1995, de 1 de julio, sobre derechos y libertades de los extranjeros en España, en su artículo 26.2, la norma que incluyó por vez primera la detención migratoria «con carácter preventivo o cautelar mientras se sustancia el expediente [de expulsión]». Precisamente esa ley fue la que instauró el modelo de control migratorio instrumental que sigue vertebrando la política actual en este contexto. ${ }^{17}$ Por aquel entonces, la detención no podía exceder de cuarenta días.

La actual ley de extranjería, la Ley Orgánica 4/2000, de 11 de enero, sobre derechos y libertades de los extranjeros en España y su integración social («LOEX»), contempla en su artículo 62 el ingreso en centros de internamiento para personas nacionales de terceros países no comunitarios, una circunstancia que el artículo precedente contempla como una de las distintas medidas cautelares a disposición del juez competente una vez incoado un procedimiento sancionador en el que pueda proponerse la expulsión. En su redacción original la duración máxima fue fiel a los cuarenta días estipulados en la década de los ochenta. Sin embargo, una reforma de 2009 amplió el plazo hasta los sesenta días hoy vigente, como consecuencia de la Directiva de retorno que contempla una detención máxima de hasta seis meses. Conviene matizar, no obstante, que esta directiva incluye la detención migratoria como el último recurso disponible para asegurar el objetivo del procedimiento.

Hoy nos hallamos por tanto ante una detención migratoria establecida por ley en España, apoyada por el derecho de la Unión Europea, y con una duración máxima de 60 días. La LOEX enumera en su artículo

\footnotetext{
16 Eurostat (2021a). First instance decisions on applications by citizenship, age and sex - annual aggregated data (rounded), MIGR_ASYDCFSTA. Última actualización: 3 de junio de 2021. Disponible en: https://bit.ly/2ThoN81.

17 SOLANES CORELLA, Á. (2010). Un balance tras 25 años de leyes de extranjería en España, 1985-2010. Revista del Ministerio de Trabajo e Inmigración, 90, p. 80.
} 
61 las distintas medidas cautelares a disposición de los tribunales para asegurar la resolución final en el procedimiento sancionador. Entre ellas se encuentra la detención migratoria (letra e), a la par que otras como la presentación periódica ante las autoridades (letra a), la residencia obligatoria (letra b), la retirada de documentación (letra c), la detención cautelar previa al internamiento (letra d), así como «cualquier otra medida cautelar que el juez estime adecuada y suficiente» (letra f). Esta norma, sin embargo, no se ajusta al contenido de la Directiva de retorno, cuyo artículo 15.1 establece expresamente que la detención migratoria solo puede operar como último recurso, esto es, solo cuando «[no] puedan aplicarse con eficacia otras medidas suficientes de carácter menos coercitivo», en especial, cuando exista riesgo de fuga o la persona afectada obstaculice su propia expulsión.

El Real Decreto 557/2011, de 20 de abril, por el que se aprueba el Reglamento de la Ley Orgánica 4/2000, sobre derechos y libertades de los extranjeros en España y su integración social, tras su reforma por Ley Orgánica 2/2009 («RELOEX»), norma que desarrolla el contenido de la LOEX, en cambio, sí establece un orden de preferencia en la aplicación de las medidas cautelares que choca frontalmente con la redacción de la normativa comunitaria. Esto es así porque el artículo 235 de dicho reglamento, en su quinto párrafo, determina la detención como primera medida en el marco del procedimiento preferente. Ello se confirma en su siguiente párrafo cuando se establece que, ante la denegación de la solicitud de internamiento (es decir, de forma supletoria a la detención), se podrán adoptar otras medidas cautelares, como la retirada de documentación o residencia obligatoria, entre otras, mencionadas en la LOEX. De esta forma, el RELOEX establece un orden jerárquico abiertamente contrario a la Directiva de retorno. La legislación de extranjería, por tanto, no establece un verdadero sistema de alternativas a privación de libertad ya que otorga un papel principal y absoluto a la detención: es «un sistema de internamiento sin alternativas». ${ }^{18}$ No está de más recordar que se trata de una medida coercitiva y punitiva del ámbito del derecho penal aplicada al derecho administrativo como consecuencia de una infracción administrativa. Siguiendo los principios rectores que deben guiar la decisión de detención analizados por Martínez, ${ }^{19} \mathrm{su}$ proporcionalidad es más que cuestionable y su carácter excepcional no es tal ya que ni siquiera cumple

\footnotetext{
${ }^{18}$ SÁNCHEZ TOMÁS, J.M. (2013a). Hacia un sistema alternativo al internamiento de inmigrantes irregulares. Eunomía, 5 , p. 84.

${ }^{19}$ MARTÍNEZ ESCAMILLA, M. (2016). Centros de internamiento para extranjeros. Estado de la cuestión y perspectivas de futuro. Revista Electrónica de Ciencia Penal y Criminología, 18-23, pp. 23 y ss.
} 
el requisito de ultima ratio; es, en palabras de Miralles Sangro una «detención inconstitucional e irregular de los extranjeros sometidos a posible expulsión». ${ }^{20}$

Aunque oficialmente carecen de carácter penitenciario, en la realidad funcionan como verdaderas cárceles, una cuestión que no solo es consecuencia del hecho de que muchos centros estén ocupando el espacio de anteriores centros penitenciarios, ${ }^{21}$ sino por el hecho de que la privación de libertad va unida a unas condiciones que no difieren mucho de la situación vivida por las personas reclusas en las cárceles. Se han destacado numerosas irregularidades, entre las que se incluyen la deficiente calidad de las propias infraestructuras, la vulneración del derecho a la intimidad, la ausencia de un servicio de asistencia social continuado y permanente, las limitaciones en el acceso a una atención sanitaria básica, la desinformación, los obstáculos para acceder a una asistencia letrada, o la falta de confidencialidad y efectividad de los sistemas de quejas ante vulneraciones de derechos. ${ }^{22}$

La detención en un CIE comporta graves consecuencias psicosociales para las personas migrantes afectadas que alteran su comportamiento y conducta más allá del periodo de reclusión, y es que se trata de un sistema carcelario que «imprime en la subjetividad de la persona la falta de control sobre la propia vida y pone de manifiesto el alcance del poder del Estado sobre el individuo a través de la aplicación de las leyes y los mecanismos de control». ${ }^{23}$ Estos centros de detención son, por ello, fronteras internas que no disuaden, pero sí pretenden generar una sensación de seguridad ad intra; ${ }^{24}$ separan a nacionales de personas extranjeras y que cumplen un papel de control social que pone en entredicho la universalidad de los derechos humanos a través de su aplicación restrictiva y que, además, pone en peligro la cohesión social. $^{25}$

\footnotetext{
${ }^{20}$ MIRALLES SANGRO, P.P. (2012). Democracia, derechos humanos y Constitución exigen el cierre inmediato de los centros de internamiento de extranjeros (CIE). Revista de Derecho UNED, 10, p. 735. Sobre este punto, y de igual forma, se posiciona también García España en GARCÍA ESPAÑA, E. (2017). Centros de Internamiento de Extranjeros: Motivos para su desaparición. Boletín Criminológico, $172(23)$, artículo 5/2017, p. 4.

${ }^{21}$ El Tribunal Constitucional aceptó la constitucionalidad de la detención migratoria siempre y cuando se diera en instalaciones que carezcan de carácter penitenciario como «garantía adicional que trata de evitar que el extranjero sea sometido al tratamiento propio de los centros penitenciarios» (STC 115/1987, de 7 de julio, fundamento jurídico primero).

${ }^{22}$ Pueblos Unidos (2015). Situación actual de los centros de internamiento de extranjeros en España y su adecuación al marco legal vigente, pp. 68-70.

${ }^{23}$ DE LUCAS, J., JARRÍN MORÁN, A. \& RODRÍGUEZ GARCÍA, D. (2012). Op. cit., p. 214.

${ }^{24}$ Migraeurop (2013). Encierro de migrantes. El «modo de gestión» privilegiado de las migraciones. Boletín n. ${ }^{\circ} 2$ de abril de 2013 , p. 2.

${ }^{25}$ BARONE, S. (2015). Op. cit., pp. 329-330.
} 
La detención migratoria es un claro ejemplo de que en la ponderación realizada por la política migratoria entre la protección de personas y el control coercitivo que deriva en vulneración de derechos, prima este último. En este punto conviene destacar que cualquier política migratoria que pretenda ser integral no puede nunca obviar la integración; es más, la integración debe ser el motor principal y «premisa indispensable, imprescindible, sine qua non, de una verdadera política migratoria». ${ }^{26}$

La clave proteccionista de dicha política, evidenciada en el caso de la detención migratoria y los CIE, no hace más que socavar la integración social de personas migrantes. No puede hablarse de verdadera cohesión social sin la equiparación en el reconocimiento jurídico, sin la igualdad de derechos en su conjunto. $^{27} \mathrm{Y}$, en este caso, solo las personas migrantes, incluso aquellas que no han cometido delito alguno, pueden ser privadas de libertad en centros en condiciones carcelarias. Es un ejemplo del fracaso de la desnacionalización de los derechos humanos. Estos son inherentes a toda persona, con independencia de su nacionalidad o carencia de ella. En teoría, por lo tanto, los derechos humanos están desnacionalizados porque no dependen de una nacionalidad concreta para ser ejercitados, pero en la práctica, la nacionalidad es un derecho humano clave e instrumental que ofrece la llave para acceder al ejercicio efectivo del resto de derechos humanos. La desnacionalización es un proceso incompleto y la detención migratoria es prueba de ello. ${ }^{28}$

¿En qué lugar queda la integración y la perspectiva de protección «de» personas frente a la protección «ante» personas? Si hablamos de detención migratoria, la integración es totalmente incompatible con aquella y es necesario resaltar que los términos inmigración e integración son indisociables, ${ }^{29}$ por lo que nunca puede ni debe perderse la mirada inclusiva en toda política migratoria. ¿Justifica el control migratorio centrado en el «otro» como amenaza y en la instrumentalización del ser humano su coste humano? Nunca, y, además, podemos estar hablando de un «derecho a la integración» que se estaría vulnerando repetidamente. Si los derechos humanos son inalienables e inherentes a toda persona, su realización efectiva no depende de la nacionalidad, y constituyen un elemento básico para la integración, podríamos estar hablando de un verdadero derecho a la integración. ¿Por qué abordar la integración de

\footnotetext{
${ }^{26}$ SOLANES CORELLA, Á. (2006). Inmigración, integración y tercer sector. Revista Española del Tercer Sector, 4, p. 45.

${ }^{27}$ DE LUCAS, J. (1996). Puertas que se cierran: Europa como fortaleza. Barcelona: Icaria, p. 37; y SOLANES CORELLA, Á. (2006). Op. cit., p. 18.

${ }^{28}$ VAN WAAS, L. (2009). Nationality and Rights. En BLITZ, B. K. \& LYNCH, M. (eds.), Statelessness and the Benefits of Citizenship: A Comparative Study (págs. 20-37). Oxford: Oxford Brookes University, pp. 21-22.

${ }^{29}$ SOLANES CORELLA, Á. (2015). Rights, Immigration and Social Cohesion in Spain. Migraciones Internacionales, 8(2), pp. 19-20.
} 
personas que van a ser expulsadas del territorio? Porque son personas, porque tienen derecho a la integración, y porque solo a veces son finalmente expulsadas.

El proceso de integración social es largo, continuo y exige constancia; es un proceso bidireccional que debe evitar cualquier tipo de mirada parcial e instrumental de la movilidad humana; ${ }^{30}$ lograr dicha integración es un objetivo fundamental del Estado democrático. ${ }^{31}$ Las medidas de integración de personas que se encuentren en un procedimiento administrativo sancionador de expulsión son necesarias ya que dichas personas acaban en su mayoría permaneciendo en España en situación administrativa irregular, en riesgo de exclusión social. Es por ello precisamente por lo que deben diseñarse e implementarse alternativas a la detención no solo con el objetivo de poner fin a dicha práctica, sino también para ofrecer herramientas que favorezcan la inclusión social de esas personas y la cohesión social en su conjunto.

\section{Las alternativas a la detención migratoria: el sistema de acogida como alternativa que favorece la integración}

El término alternativas a la detención migratoria engloba un conjunto de prácticas que pueden implementarse para evitar la detención, que respetan los principios de necesidad y proporcionalidad, y que pueden definirse como medidas no privativas de libertad que respetan los derechos humanos fundamentales y que permiten elegir a las personas opciones distintas de la detención. ${ }^{32}$

\section{1. ¿Por qué hacen falta alternativas?}

En un contexto de vulneración de derechos y condiciones carcelarias, ambos factores generadores o agravantes de situaciones de vulnerabilidad, y teniendo en cuenta la normativa comunitaria, la respuesta a por qué hacen falta alternativas a la detención migratoria es obvia: solo a través de alternativas no privativas de libertad se pueden evitar esos abusos a la vez que se da cumplimiento efectivo a las obligaciones de España en este ámbito. Hay que añadir, que solo las alternativas pueden, además, contribuir a la integración social. Reitero la pertinencia de abordar la integración de personas sometidas a un procedimiento de expulsión. Según Eurostat, en los últimos diez años, el porcentaje de personas

\footnotetext{
${ }^{30}$ AÑÓN, M.J. (2010). Integración: una cuestión de derechos. Arbor: Ciencia, Pensamiento y Cultura, 744, p. 635.

${ }^{31}$ MULERO GARCÍA, J.S. (2011). Integración social, derecho a la diferencia y relaciones jurídico-privadas internacionales. Cuadernos Electrónicos de Filosofía del Derecho, 24, p. 151.

${ }^{32}$ Consejo de Europa (2017). Human Rights and Migration. Legal and practical aspects of effective alternatives to detention in the context of migration. Estrasburgo: Consejo de Europa, p. 18.
} 
expulsadas con relación al número de personas con una orden de retorno en España ha sido siempre inferior al 50\%, siendo lo más habitual porcentajes en torno al 30\%. ${ }^{33}$ Por si fuera poco, la detención migratoria no garantiza la expulsión de esas personas, y se implementa aun sabiendo que no existe posibilidad alguna de ejecutar la expulsión. ${ }^{34}$ Desde 2013, y con la salvedad de 2018, más de la mitad de las personas detenidas en los CIE han sido liberadas por no poder ejecutar su expulsión. Las repatriaciones forzosas desde estos centros han variado desde tasas del 47,8\% en 2014 hasta el 29,02\% en 2016 , con un récord del 59,52\% en 2009. ${ }^{35}$ Una amplia mayoría de las personas con una orden de expulsión, incluso quienes son detenidas en los CIE, permanecen finalmente en España, y lo hacen en situación administrativa irregular. Hacen falta alternativas que permitan trabajar en su integración social para evitar situaciones de exclusión social y de vulnerabilidad a las que ya se hallan expuestas, incluso sin que haya detención de por medio.

Es preciso incidir en el hecho de que abogar por la implementación de alternativas es abogar por el cumplimiento de la normativa, además de favorecer estrategias y políticas migratorias que respeten las obligaciones internacionales y que eviten una perspectiva coercitiva y discriminatoria con respecto a las personas migrantes, las únicas que, recordemos, pueden ver privada su libertad sin haber sido siquiera acusadas de cometer un hecho delictivo. Los beneficios de las alternativas son múltiples: se cumple de esa forma con los estándares del derecho internacional de los derechos humanos; se evita el innecesario sufrimiento, daño físico y psicológico, las consecuencias perniciosas de toda privación de libertad, y la generación de situaciones de vulnerabilidad o agravación de las mismas; se logra una mayor cooperación individual que redunda en una mayor tasa de cumplimiento de las resoluciones del procedimiento, incluida una mayor tasa de retorno con motivo de salidas voluntarias; y se trata, además, de medidas más económicas, teniendo en cuenta que la detención ha demostrado ser entre el doble y diecisiete veces más cara que aquellas. ${ }^{36}$

\footnotetext{
${ }^{33}$ Eurostat (2021b). Third country nationals ordered to leave - annual data (rounded), MIGR_EIORD. Última actualización: 20 de mayo de 2021. Disponible en: https://bit.ly/3A37WH0; y Eurostat (2021c). Third country nationals returned following an order to leave - annual data (rounded), MIGR_EIRTN. Última actualización: 20 de mayo de 2021. Disponible en: https://bit.ly/3x1007a.

34 AZCÁRRAGA MONZONÍS, C. (2014). Centros de internamiento de extranjeros. Principales denuncias y novedades legislativas. Barataria. Revista Castellano-Manchega de Ciencias Sociales, 17, p. 147.

${ }^{35}$ Servicio Jesuita a Migrantes-España (2019). Informe CIE 2018: Discriminación de origen. Madrid: Servicio Jesuita a Migrantes, p. 26.

36 Consejo de Europa (2019). Practical guidance on Alternatives to Immigration Detention: Fostering Effective Results. CDDH(2019)R91Addendum5, p. 8.
} 
Distintos organismos y organizaciones internacionales se han pronunciado en múltiples ocasiones con respecto a la necesidad de reducir o limitar al máximo la detención migratoria, que debe ser implementada solo como último recurso, a la vez que destacan la importancia de desarrollar y poner en práctica alternativas.

Recientemente, el Parlamento Europeo aprobó una resolución sobre la aplicación de la Directiva de retorno en la que, asumiendo que las alternativas son, además, menos costosas y que la detención migratoria solo está contemplada por dicha norma como medida de último recurso, admitió que no era así en la práctica y que los Estados deben ofrecer alternativas «viables y basadas en la comunidad que tengan un efecto menos negativo en los migrantes»». ${ }^{37}$ Además, la Agencia de los Derechos Fundamentales de la Unión Europea («FRA») entiende que la detención migratoria puede ser «arbitraria» si el objetivo por el que se ha establecido puede también alcanzarse mediante medidas menos restrictivas, como la presentación periódica ante las autoridades. ${ }^{38}$

En el seno de Naciones Unidas, han sido varios órganos los que han abordado la cuestión. Así, la propia Asamblea General de Naciones Unidas, a través del objetivo trece del Pacto mundial para la migración segura, ordenada y regular determina el empleo de «la detención de migrantes solo como último recurso» y la búsqueda de «otras alternativas», para lo cual establece una serie de puntos que pueden servir de guía a los Estados para poner en práctica de forma efectiva el uso de dichas alternativas. ${ }^{39}$ También en 2008 y 2012, mediante dos resoluciones, pidió a los Estados la adopción de medidas no privativas de libertad para personas en situación administrativa irregular. ${ }^{40}$ Por su parte, el Relator Especial sobre los derechos humanos de los migrantes adoptó un informe en 2012 en el que establece que, además del hecho de que las alternativas deben siempre imperar como primer recurso y que ello debe establecerse en la ley, existen muchos motivos para evitar la detención y la búsqueda de alternativas: más allá del hecho de que son menos costosas económicamente, como señala el Parlamento Europeo, el Relator Especial destaca que sí tienen un «coste» que hay que evitar: «las dificultades de integración y otros problemas

\footnotetext{
${ }^{37}$ Parlamento Europeo (2020). Resolución de 17 de diciembre de 2020 sobre la aplicación de la Directiva sobre retorno (2019/2208(INI)), párrafos 31 y 32 .

${ }^{38}$ Agencia de los Derechos Fundamentales de la Unión Europea (2010). Detention of third-country nationals in return procedures. Viena: FRA, p. 7.

39 Asamblea General de Naciones Unidas (2018). Resolución 73/195: Pacto Mundial para la Migración Segura, Ordenada y Regular (A/RES/73/195), aprobada el 19 de diciembre de 2018, objetivo 13.

${ }^{40}$ Asamblea General de Naciones Unidas (2008). Resolución 63/184 (A/RES/63/184), aprobada el 18 de diciembre de 2008; y Asamblea General de Naciones Unidas (2012). Resolución 67/172 (A/RES/67/172), aprobada el 20 de diciembre de 2012.
} 
sociales» que lleva aparejada la detención. ${ }^{41}$ Un año después, en un nuevo informe, el propio Relator Especial hace referencia a la Directiva de retorno para reiterar que la detención solo cabe como último recurso y que, a pesar de ello, «en la práctica, parece que la Unión Europea de manera institucional y los Estados miembros con carácter individual han analizado pocas alternativas viables a dicha medida»; de hecho, destaca la ausencia total de alternativas en los países que visitó para la realización de dicho informe. En sus conclusiones pide no emplear la detención migratoria como mecanismo de control migratorio e insiste en la implementación de medidas alternativas. ${ }^{42}$

El Comité de Derechos Humanos también se ha referido a la detención migratoria en su Observación general n. ${ }^{\circ}$ 35. Así, afirma que la decisión de detener a migrantes por su situación administrativa debe tener en cuenta otros medios menos invasivos para lograr el mismo fin, como obligaciones de presentación ante las autoridades, garantías u otras condiciones para evitar el riesgo de fuga; asimismo, tiene en cuenta los elementos de proporcionalidad, necesidad y razonabilidad para examinar su posible arbitrariedad. ${ }^{43}$ En este texto de 2014 se recoge lo que el propio comité venía estableciendo a través de dictámenes en respuesta a comunicaciones individuales como el aprobado en 2002 en el caso $C$. $c$. Australia, en cuyo contenido denuncia al Estado australiano por detener de forma prolongada a una persona migrante con el objetivo de expulsarla sin haber «demostrado que, dadas las circunstancias especiales del autor, no hubiera medios menos drásticos para alcanzar el mismo objetivo, es decir, la aplicación de la política de inmigración del Estado parte, como son la imposición de la obligación de presentarse a las autoridades competentes, el depósito de fianza u otras condiciones que tuviesen en cuenta la deterioración del estado del autor», todo lo cual supuso, según este órgano, una violación del artículo 9.1 del Pacto Internacional de Derechos Civiles y Políticos que consagra el derecho a la libertad y seguridad personal. ${ }^{44}$

La problemática de la detención y el uso de alternativas ha sido también explorada y analizada por el Grupo de Trabajo sobre Detención Arbitraria. Ya en 1998 estableció que para determinar si una detención es arbitraria se debe tener en cuenta si la persona migrante puede beneficiarse total o parcialmente de

\footnotetext{
${ }^{41}$ Consejo de Derechos Humanos (2012). Informe del Relator Especial sobre los derechos humanos de los migrantes (A/HRC/20/24), párrafos $48-50$ y 53.

${ }^{42}$ Consejo de Derechos Humanos (2013). Informe del Relator Especial sobre los derechos humanos de los migrantes (A/HRC/23/46), párrafos 48 y 92 .

${ }^{43}$ Comité de Derechos Humanos (2014). Observación general n. 35 (CCPR/C/GC/35), párrafos 12 y 18.

${ }^{44}$ Comité de Derechos Humanos (2002). Dictamen sobre la comunicación n. ${ }^{\circ}$ 900/1999 (CCPR/C/76/D/900/1999), párrafo 8.2.
} 
distintas garantías, entre la que se incluye, como decimotercera, la «posibilidad, para el extranjero, de beneficiarse de otras medidas diferentes de la retención administrativa». ${ }^{45}$ En una adición a dicho informe se destaca claramente el término «detención» y se determina que «antes de recurrir a la detención deberían siempre examinarse otras medidas alternativas distintas de la detención, tales como la obligación de comparecer ante la policía». ${ }^{46}$ Este Grupo de Trabajo ha reiterado esta posición posteriormente: así, en 2008 recordó lo estipulado en el informe de 1998 recomendado de nuevo la detención solo como último recurso (2008, párrafos 53 y 80), mientras que en 2009 y 2010 fue más allá al mostrar su preocupación por la detención de migrantes en situación administrativa irregular, al solicitar la supresión gradual de dicha medida porque esas personas no han cometido ningún delito y, finalmente, al concluir que «la penalización de la migración irregular sobrepasa el interés legítimo de todo Estado de proteger su territorio y reglamentar la corriente regular de migrantes». ${ }^{47}$ Más recientemente ha abogado por alternativas realistas y que no dependan de la capacidad económica individual de la persona para que puedan aplicarse, de forma que se ponen, como ejemplos, la presentación periódica ante las autoridades, soluciones basadas en la comunidad, o aprovechar las nuevas tecnologías que permitirían cumplir con las obligaciones de presentación periódica por medios telemáticos o telefónicos. ${ }^{48}$

\section{2. ¿Qué alternativas hay?}

El artículo 61.1 de la LOEX incluye alternativas no privativas de libertad dentro de las denominadas medidas cautelares que pueden proponerse durante el procedimiento de expulsión para asegurar su resolución final. Se trata de la presentación periódica ante las autoridades, la residencia obligatoria en un lugar determinado, la retirada de documentación acreditativa de la identidad, como el pasaporte, y cualquier otra medida que estime adecuada el juez competente. Cualquiera de esas medidas es menos lesiva, menos invasiva, menos coercitiva y punitiva que la privación de libertad. Si la política migratoria se caracteriza por su opacidad, ${ }^{49}$ muestra de ello es la situación específica de la detención migratoria y el

\footnotetext{
${ }^{45}$ Comisión de Derechos Humanos (1998a). Informe del Grupo de Trabajo sobre la Detención Arbitraria (E/CN.4/1999/63), párrafo 69.

46 Comisión de Derechos Humanos (1998b). Informe del Grupo de Trabajo sobre la Detención Arbitraria - Adición (E/CN.4/1999/63/Add.3), párrafo 33.

${ }^{47}$ Consejo de Derechos Humanos (2009). Informe del Grupo de Trabajo sobre la Detención Arbitraria (A/HRC/10/21), párrafo 75; y Consejo de Derechos Humanos (2010). Informe del Grupo de Trabajo sobre la Detención Arbitraria (A/HRC/13/30), párrafo 58.

${ }^{48}$ Consejo de Derechos Humanos (2018a). Informe del Grupo de Trabajo sobre la Detención Arbitraria (A/HRC/39/45), párrafo 17; y Consejo de Derechos Humanos (2020a). Informe del Grupo de Trabajo sobre la Detención Arbitraria (A/HRC/45/16), párrafo 57.

${ }^{49}$ LÓPEZ-SALA, A. \& GODENAU, D. (Coords.) (2017). Op. cit., p. 19.
} 
uso (o no uso) de sus alternativas. ${ }^{50}$ En efecto, se desconoce si se ponen en práctica las medidas cautelares no privativas de libertad y en qué grado. Lo que sí se sabe es que dicha política migratoria siempre ha priorizado la detención migratoria como medida cautelar principal, y que las alternativas no privativas de libertad son excepcionales y en todo caso subordinadas a la detención. ${ }^{51}$

Por si fuera poco, la Ley Orgánica 4/2015, de 30 de marzo, de protección de la seguridad ciudadana, parece limitar e incluso eliminar la cobertura legal de la medida cautelar consistente en la retirada de pasaporte o documento acreditativo de la identidad en tanto su artículo 13.2 determina que no se puede privar a personas extranjeras de su documentación de origen salvo en el curso de investigaciones judiciales de carácter penal, lo cual excluiría cualquier actuación a tal efecto en un procedimiento administrativo sancionador ${ }^{52}$ En tal caso, el elenco de alternativas se reduce a la presentación periódica ante las autoridades, a la residencia obligatoria en un lugar determinado y en cualquier otra medida adecuada que sirve como «cajón de sastre».

El Gobierno de España suele evitar pronunciarse en el contexto de las alternativas a la detención. Con motivo del Examen Periódico Universal a España en el seno del Consejo de Derechos Humanos de Naciones Unidas, ante la recomendación hondureña de ofrecer una acogida humanitaria a personas en situación administrativa irregular en España como alternativa a la detención migratoria, la respuesta española obvió toda alusión a las alternativas para centrarse en los CIE, y tomando nota de la recomendación, sin aceptarla, afirmó que «el internamiento de un inmigrante irregular en un Centro de Internamiento de Extranjeros (CIE) se produce exclusivamente cuando existe una perspectiva de que va a ser retornado, con el único objetivo de garantizar el retorno cuando no existe otra alternativa y con la autorización de un Juez». ${ }^{53}$ La obsesión de control migratorio a través de la detención migratoria se

\footnotetext{
${ }^{50}$ Servicio Jesuita a Migrantes-España (2021). Informe CIE 2020: Razón jurídica y sinrazón política. Madrid: Servicio Jesuita a Migrantes, p. 8; y European Migration Network (2014). The use of detention and alternatives to detention in the context of immigration policies. Synthesis report for the EMN Focused Study 2014, p. 57.

${ }^{51}$ SÁNCHEZ TOMÁS, J.M. (2013b). ¿Hay alternativas al internamiento de inmigrantes irregulares? Mugak, 64-65, p. 34.

${ }^{52}$ SÁNCHEZ TOMÁS, J.M. (2015). Algunas ideas sobre la nueva regulación de la retirada de pasaporte de ciudadanos extranjeros en el art. 13.2 de la Ley Orgánica 3/2015, de 30 de marzo, de protección de la seguridad ciudadana [web], p. 6, disponible en: https://bit.ly/2TYwgcI. Sánchez Tomás se basa en los principios de temporalidad y especialidad de normas en conflicto; sin embargo, conviene resaltar que dicha ley declara en su disposición final tercera que el artículo 13 tiene carácter no orgánico, por lo que el artículo 61.1, letra c de la LOEX mantiene su rango orgánico y jerárquicamente superior.

${ }^{53}$ Consejo de Derechos Humanos (2020b). Anejo explicativo de las observaciones de España a las recomendaciones recibidas por España con ocasión del tercer ciclo del Examen Periódico Universal. Respuesta a la recomendación 150.257 de Honduras, p. 84.
} 
plasma también en la inversión prevista para construir un nuevo CIE y mejorar las infraestructuras de otros centros con un presupuesto que asciende a 33627379 euros entre 2019 y $2024 .{ }^{54}$

\subsection{Alternativas existentes no previstas en la normativa de extranjería}

El Consejo de Europa aprobó en octubre de 2019 un manual práctico sobre alternativas a la detención migratoria para asegurar resultados efectivos. En él evalúa las ventajas e inconvenientes de una serie de medidas sin ánimo de exhaustividad entre las que se encuentran las ya mencionadas y previstas en el artículo 61 de la LOEX. Además de esas dos, se abordan como medidas alternativas no privativas de libertad y respetuosas con la dignidad y el derecho a la intimidad de las personas: (1) la posibilidad de conceder una autorización de estancia temporal, como los visados humanitarios, que pueden ser renovadas; (2) la estancia en centros abiertos que permitan la libertad de circulación; (3) la supervisión por parte del Estado o una organización social a través de visitas al domicilio de la persona migrante que se halla en libertad; (4) los programas de retorno voluntario y asistido; o (5) la gestión de casos a través de la asignación de un profesional encargado de ofrecer información, acceso a servicios básicos, a la asistencia letrada, y de representar a la persona en el procedimiento administrativo. ${ }^{55}$

\subsection{Programas de acogida: ¿una alternativa viable y eficaz?}

El 6 de mayo de 2020 los CIE se quedaron vacíos y la detención migratoria desapareció durante varios meses en España con motivo de la pandemia. El cierre de fronteras y la imposibilidad de ejecutar las órdenes de expulsión dejaron sin base legal a una detención que se aplica con el único fin de asegurar el retorno; además, la estancia en los distintos centros suponía un serio peligro para la salud y generaba graves problemas para cumplir con las medidas sanitarias obligatorias impuestas para evitar la

\footnotetext{
${ }^{54}$ Gobierno de España (18 de enero de 2019). Mejora de las instalaciones de los Centros de Internamiento de Extranjeros (CIE) [web]. Disponible en: https://bit.ly/2UsTUOH.

55 Véase nota 32. En el ámbito de la gestión de casos, conviene destacar el modelo CAP revisado (Revised Community and Assessment Model) de International Detention Coalition («IDC») que incluye la gestión de casos. Se trata de un modelo que permite a personas en situación administrativa irregular permanecer en libertad en el territorio mientras dura el procedimiento, sobre la base del respeto de sus derechos humanos, la cobertura de sus necesidades básicas, el acceso a asistencia letrada e interpretación a través del acompañamiento de una persona profesional asignada para cada caso concreto. Para más información, véase SAMPSON, R., CHEW, V., MITCHELL, G. \& BORWING, L. (2015). There Are Alternatives: A Handbook for Preventing Unnecessary Immigration Detention (Revised). Melbourne: International Coalition Detention.
} 
propagación del virus. Más allá de su legalidad, cuestiones humanitarias lo demandaban, tal y como se reflejó en el auto que disponía el cierre del CIE de Barranco Seco el 31 de marzo de $2020 .^{56}$

Muchas de las personas liberadas fueron trasladadas a dispositivos de acogida de organizaciones sociales que desarrollan programas de atención humanitaria diseñados para la acogida e integración social de personas en situación administrativa irregular llegadas a costas cuya devolución no ha podido efectuarse. Estos proyectos actuaron, de facto, como alternativas a la detención migratoria a pesar de no estar previstos específicamente para tal fin, y pueden, con las adaptaciones necesarias, erigirse como válidas y efectivas alternativas que, además, favorezcan la inclusión social de las personas sometidas a un procedimiento de expulsión en los que, recordemos, existe una alta probabilidad de permanencia en España de las personas afectadas.

Hay dos sistemas principales de acogida en el contexto de la integración de personas migrantes en España. Por un lado, se halla el sistema de acogida para personas solicitantes y beneficiarias de protección internacional y del estatuto de apátrida que tiene una duración de hasta 18 meses, prorrogables en casos de extrema vulnerabilidad hasta los 24 meses y que está diseñado para la acogida y la implementación de itinerarios individualizados de integración de personas que reúnan aquel perfil de protección internacional. En él, las condiciones materiales de acogida son ofrecidas por equipos multidisciplinares con perfiles profesionales específicos como trabajadores sociales, abogados, psicólogos, formadores, mediadores, orientadores laborales, personal administrativo y técnicos de acogida. No debe confundirse con el referido sistema de atención humanitaria para personas en situación administrativa irregular llegadas a costas con un contenido distinto, cuyo contenido y extensión difiere sustancialmente de aquel. Es precisamente este, el de atención humanitaria, el que se detallará a continuación y se defenderá como base para una verdadera alternativa no privativa de libertad a la detención migratoria debido a que sus personas beneficiarias son aquellas que se hallan en situación administrativa irregular en el territorio.

Los programas de atención humanitaria tienen el objetivo fundamental de favorecer la integración social de esas personas que se ven abocadas a la irregularidad en un Estado que no puede devolverlas a su país de origen, pero que tampoco ofrece vías para su regularización más allá de las autorizaciones de residencia por circunstancias excepcionales conocidas como «arraigos», que inciden, precisamente, en

${ }^{56}$ Auto n. ${ }^{\circ}$ 15/2020, de 31 de marzo de 2020 del Juzgado de Instrucción n. ${ }^{\circ} 8$ de Las Palmas de Gran Canaria. 
su integración o arraigo en la sociedad de acogida. El personal de los equipos está formado por técnicos de acogida $y$, en ocasiones, concurren perfiles profesionales como trabajadores sociales, abogados o psicólogos; en ocasiones, el trabajo es apoyado por personal voluntario. La estancia en este sistema es de seis meses y se establece una acogida en dispositivos que se hallan en apartamentos dentro de la localidad, lo cual garantiza el respeto al principio de unidad familiar y de privacidad recomendados por la Oficina Europea de Apoyo al Asilo en este contexto. ${ }^{57}$ Además de dicho alojamiento, la acogida incluye asimismo prestaciones económicas destinadas a la manutención básica como la comida, productos de higiene y limpieza, un acompañamiento para realizar gestiones administrativas o para cuestiones sanitarias, y distintas actuaciones en forma de taller formativo, enseñanza del idioma o realización de actividades culturales propias de la localidad para la adquisición de herramientas simbólicas y comunicativas que fomenten su inclusión social.

Se trata de un exitoso programa de integración social viable y sostenible a largo plazo que combate de forma efectiva la exclusión social de quienes no son deseados por la normativa de extranjería, pero que, sin embargo, no pueden ser devueltos conforme a los mecanismos dispuestos en la legislación ni quieren ser devueltos a sus países de origen por cualesquiera motivos. A través de la cobertura de sus necesidades básicas y de herramientas esenciales de inclusión temprana se les ofrecen mecanismos cruciales para su establecimiento en la localidad y para poder arraigar su estancia en la comunidad, a pesar de las dificultades que supone hallarse en situación de irregularidad como consecuencia de aquella normativa.

La pregunta que se puede plantear en este punto es si puede implementarse este sistema de atención humanitaria como una alternativa a la detención migratoria. La respuesta debe ser afirmativa, aunque con matices. Es cierto que los programas actuales de atención humanitaria no van ligados a ningún procedimiento administrativo concreto; es decir, no van asociados a los procedimientos sancionadores de retorno. Las personas que se hallan en los dispositivos de acogida durante hasta seis meses son aquellas que tienen una orden de devolución pendiente, pero cuya ejecución no ha sido posible. Más que una alternativa a la detención, ahora funcionan como una alternativa a la exclusión social derivada de la situación irregular de personas cuya devolución no puede ejecutarse.

${ }^{57}$ European Asylum Support Office (2016). EASO guidance on reception conditions: operational standards and indicators, pp. 15-16. 
Pero este mismo sistema, con los ajustes necesarios que lo vinculen a dichos procedimientos administrativos, puede erigirse como una alternativa viable y eficaz. Sería eficaz porque se trabaja sobre la base de una relación de confianza con las personas migrantes, generando así una mayor tasa de cumplimiento de las decisiones tomadas durante el procedimiento; y sería viable porque no se parte de cero, sino de un sistema público maduro, sólido y estable implementado por organizaciones sociales con experiencia en la gestión de este tipo de plazas y con una clara misión en favor de la inclusión social. Además, esta alternativa favorecería el trabajo en la línea del retorno voluntario e, incluso, del retorno voluntario del tipo «productivo», relacionado con el concepto de codesarrollo y también gestionado por entidades sin ánimo de lucro, y que tiene por objetivo no solo el retorno, sino también la reintegración de las personas en sus países de origen a través de estrategias individualizadas diseñadas para ofrecer habilidades laborales y de emprendimiento y que ofrecen un seguimiento de proyectos asociados a este programa en el país de origen. ${ }^{58}$

\section{Conclusiones}

1. La detención migratoria es una de las distintas herramientas a disposición de una política migratoria coercitiva con las personas migrantes, en especial con aquellas en situación administrativa irregular y proclives a hallarse en exclusión social. Sin embargo, la detención migratoria no es un mecanismo previsto en la normativa comunitaria de retorno ni acogida por el derecho internacional de los derechos humanos como una medida necesaria para cumplir con el fin que supuestamente tiene previsto asegurar: ejecutar las decisiones de retorno. Y esto es así por dos razones principales: en primer lugar, porque la Directiva de retorno contempla la detención migratoria solo cuando no existan otras alternativas menos coercitivas para lograr el mismo fin; $y$, en segundo lugar, porque dicho fin no se garantiza con una medida privativa de libertad como es la detención, tal y como se desprende de las estadísticas de personas detenidas en los CIE que son expulsadas del territorio. La mayoría deben ser liberadas por no poder ejecutar la orden de retorno dentro del plazo máximo de detención, que es de sesenta días.

Además de innecesaria, la detención es una medida punitiva desproporcionada de carácter penal para sancionar un hecho no delictivo y cuyas condiciones pone en serios problemas al Estado para respetar,

\footnotetext{
${ }^{58}$ Ministerio de Inclusión, Seguridad Social y Migraciones (2021). Resolución de 27 de abril de 2021 de la Dirección General de Programas de Protección Internacional y Atención Humanitaria, por la que se convocan subvenciones para proyectos de retorno voluntario de persones nacionales de terceros países; anexo A (proyectos subvencionables), apartado 2.
} 
proteger y realizar los derechos humanos de las personas afectadas. No obstante, se aplica con carácter preferente en España, cuyo ordenamiento jurídico, en virtud del reglamento que desarrolla la ley de extranjería, proclama las alternativas no privativas de libertad solo cuando no pueda efectuarse la detención en el procedimiento preferente de expulsión. De este modo, la normativa de extranjería impone como principal medida cautelar una detención que, siguiendo a Miralles Sangro y a García España, es inconstitucional y contraria a la Directiva de retorno y hace caso omiso a los estándares del derecho internacional de los derechos humanos y a las numerosas recomendaciones de organismos internacionales al respecto.

Por todo lo expuesto, la detención migratoria en España es arbitraria, al no cumplir con las exigencias de proporcionalidad, necesidad, y razonabilidad requeridas, entre otros, por el Comité de Derechos Humanos, del Grupo de Trabajo sobre la Detención Arbitraria ${ }^{59}$ y de la FRA.

2. Lo que comúnmente se conoce como «alternativas a la detención migratoria» o «medidas cautelares» no privativas de libertad en el ordenamiento jurídico español no deberían considerarse alternativas, sino la única solución a disposición de los jueces competentes. Para ello, la política migratoria debe dar un giro de ciento ochenta grados hacia la inclusión frente al actual rechazo, hacia la protección de personas frente a la protección ante personas, y hacia estrategias de acogida y regularización frente a una perspectiva centrada en el retorno. Toda política en este campo debe incluir la integración como eje que vertebre el diseño e implementación de las competencias en esta materia.

La detención es contraria a cualquier propósito de integración social y es un factor generador y agravante de situaciones de vulnerabilidad. Es cierto que está prevista en el contexto de personas que van a ser expulsadas o devueltas a sus países de origen, pero no es menos cierto que la mayoría de las personas sometidas a este tipo de procedimientos no son finalmente retornadas. Más allá de evitar situaciones de vulnerabilidad y eliminar el impacto negativo que supone la privación de libertad y las condiciones en las que se da en centros carcelarios, la estrategia debe ir encaminada en favor de la inclusión social de personas que, en su mayor parte, permanecerán en España en situación administrativa irregular y, por ese motivo, en situación (o en riesgo) de exclusión social y residencial.

\footnotetext{
${ }^{59}$ Consejo de Derechos Humanos (2018b). Grupo de Trabajo sobre la Detención Arbitraria: Revised Deliberation No. 5 on deprivation of liberty of migrants, p. 3.
} 
3. Hay pocas medidas cautelares previstas en la normativa de extranjería como alternativas a la detención migratoria, cuyo uso es además es excepcional y siempre subordinado a aquella. Sin embargo, la letra $f$ del artículo 61.1 de la LOEX establece que el juez de instrucción podrá adoptar «cualquier otra medida cautelar que (...) estime adecuada y suficiente». Ello permite diseñar e implementar estrategias no privativas de libertad no contempladas por la normativa.

Por otro lado, la mayor parte de las decisiones de retorno en España no son finalmente ejecutadas, por lo que la mayoría de las personas afectadas acaban permaneciendo en España en situación administrativa irregular. Este patrón se refleja también en la estadística de personas expulsadas desde los CIE. Conviene, por lo tanto, plantear alternativas a la detención que no sean privativas de libertad y que, asimismo, cumplan con uno de los elementos que deben informar y guiar toda política migratoria: la integración social.

Existen programas de atención humanitaria que fueron empleados como destino para la acogida de personas liberadas de los CIE cuando se decidió vaciarlos durante la pandemia debido a que la detención migratoria perdió su razón de ser al no poder ejecutarse las decisiones de retorno y por cuestiones humanitarias relacionadas con la situación de emergencia sanitaria. Este sistema de acogida está diseñado actualmente también para personas en situación administrativa irregular con el objetivo de combatir su exclusión social y brindarles herramientas tempranas de inclusión que favorezcan su integración en la comunidad a pesar de estar abocadas a la irregularidad administrativa durante años provocada por la falta de vías de regularización en la normativa de extranjería. Dicho sistema, con los ajustes necesarios que lo vinculen al procedimiento administrativo de retorno, sería una alternativa viable y eficaz para fomentar la integración de personas que finalmente van a permanecer en el territorio sin alterar los objetivos de retorno de la política migratoria. Aquellas personas que finalmente vayan a ser expulsadas podrían beneficiarse un sistema que se centre en la perspectiva del retorno voluntario productivo con el fin de asegurar su reintegración en la sociedad de origen a través de distintas herramientas laborales y del apoyo en el diseño e implementación de proyectos microempresariales en sus países de origen.

Este tipo de alternativa evitaría el uso de la detención migratoria, por lo que el Estado estaría cumpliendo con la normativa comunitaria y con los estándares del derecho internacional de los derechos humanos y evitando los abusos de derechos persistentes en los CIE actualmente sin que los objetivos de retorno del 
Estado se malogren, y siempre con una perspectiva de integración para quienes finalmente se queden en el territorio y de reintegración para quienes acaben retornando. 


\section{Bibliografía}

AÑÓN, M.J. (2010). Integración: una cuestión de derechos. Arbor: Ciencia, Pensamiento y Cultura, 744, pp. 625-638.

AZCÁRRAGA MONZONÍS, C. (2014). Centros de internamiento de extranjeros. Principales denuncias y novedades legislativas. Barataria. Revista Castellano-Manchega de Ciencias Sociales, 17, pp. 143-163.

BARBERO, I. \& DONADIO, G. (2019). La externalización interna de las fronteres en el control migratorio de la UE. Revista CIDOB d'afers internacionals, 122, pp. 137-162.

BARONE, S. (2015). Los centros de internamiento de extranjeros (CIEs) entre control migratorio y control social: una frontera interna y polimorfa. Revista de Dialectología y Tradiciones Populares, 70(2), pp. 325-330.

BAUMAN, Z. (2007). Tiempos líquidos. Vivir en una época de incertidumbre. Barcelona: Tusquets.

DE LUCAS, J. (1996). Puertas que se cierran: Europa como fortaleza. Barcelona: Icaria.

DE LUCAS, J., JARRÍN MORÁN, A. \& RODRÍGUEZ GARCÍA, D. (2012). Los Centros de Internamiento para Extranjeros en España: una evaluación crítica. Revista CIDOB d'afers internacionals, 99, pp. 201-220.

GABRIELLI, L. (2017). La externalización europea del control migratorio. ¿La acción española como modelo? Anuario CIDOB de la Inmigración 2017, pp 127-152.

GARCÍA ESPAÑA, E. (2017). Centros de Internamiento de Extranjeros: Motivos para su desaparición. Boletín Criminológico, 172(23), artículo 5/2017, pp. 1-6.

LÓPEZ-SALA, A. \& GODENAU, D. (Coords.) (2017). Estados de contención, Estados de detención. El control de la inmigración irregular en España. Barcelona: Anthropos.

MARTÍNEZ ESCAMILLA, M. (2016). Centros de internamiento para extranjeros. Estado de la cuestión y perspectivas de futuro. Revista Electrónica de Ciencia Penal y Criminología, 18-23, pp. 1-38.

MIRALLES SANGRO, P.P. (2012). Democracia, derechos humanos y Constitución exigen el cierre inmediato de los centros de internamiento de extranjeros (CIE). Revista de Derecho UNED, 10, pp. 731-742.

MULERO GARCÍA, J.S. (2011). Integración social, derecho a la diferencia y relaciones jurídico-privadas internacionales. Cuadernos Electrónicos de Filosofía del Derecho, 24, pp. 149-169.

PILZ, B. \& STEVENS, J. (2020). Case Management: Learnings, Tips and Positive Practices. European Alternatives to Detention Network.

SACK, R. D. (1986). Human Territoriality: Its theory and history. Cambridge: Cambridge University Press.

SAMPSON, R., CHEW, V., MITCHELL, G. \& BORWING, L. (2015). There Are Alternatives: A Handbook for Preventing Unnecessary Immigration Detention (Revised). Melbourne: International Coalition Detention.

SÁNCHEZ TOMÁS, J.M. (2013a). Hacia un sistema alternativo al internamiento de inmigrantes irregulares. Eunomía, 5, pp. 75-94.

SÁNCHEZ TOMÁS, J.M. (2013b). ¿Hay alternativas al internamiento de inmigrantes irregulares? Mugak, 64-65, pp. 31-34.

SÁNCHEZ TOMÁS, J.M. (2015). Algunas ideas sobre la nueva regulación de la retirada de pasaporte de ciudadanos extranjeros en el art. 13.2 de la Ley Orgánica 3/2015, de 30 de marzo, de protección de la seguridad ciudadana [web]. Disponible en: https://bit.ly/2TYwgcI.

SOLANES CORELLA, Á. (2006). Inmigración, integración y tercer sector. Revista Española del Tercer Sector, 4, pp. 1552.

SOLANES CORELLA, Á. (2010). Un balance tras 25 años de leyes de extranjería en España, 1985-2010. Revista del Ministerio de Trabajo e Inmigración, 90, pp. 77-101.

SOLANES CORELLA, Á. (2015). Rights, Immigration and Social Cohesion in Spain. Migraciones Internacionales, 8(2), pp. 9-40.

SOLANES CORELLA, Á. (2016). Una reflexión iusfilosófica y política sobre las fronteras. Anuario de Filosofia del Derecho, 32, p. 145-184. 
SUÁREZ NAVAZ, L. (2005). Ciudadanía y Migración: ¿un oxímoron? Puntos de Vista, 4, p. 29-48.

SWANN, W. B. \& BOSSON, J. K. (2010). Self and Identity. En FISKE, S. T., GILBERT, D. T. \& LINDZEY, G. (eds.), Handbook of Social Psychology, Volume I (pp. 589-628). Princeton: Wiley.

VAN WAAS, L. (2009). Nationality and Rights. En BLITZ, B. K. \& LYNCH, M. (eds.), Statelessness and the Benefits of Citizenship: A Comparative Study (pp. 20-37). Oxford: Oxford Brookes University.

\section{Referencias}

Agencia de los Derechos Fundamentales de la Unión Europea (2010). Detention of third-country nationals in return procedures. Viena: FRA.

Asamblea General de Naciones Unidas (2008). Resolución 63/184 (A/RES/63/184), aprobada el 18 de diciembre de 2008.

Asamblea General de Naciones Unidas (2012). Resolución 67/172 (A/RES/67/172), aprobada el 20 de diciembre de 2012.

Asamblea General de Naciones Unidas (2018). Resolución 73/195: Pacto Mundial para la Migración Segura, Ordenada y Regular (A/RES/73/195), aprobada el 19 de diciembre de 2018.

Auto n..$^{\circ}$ 15/2020, de 31 de marzo de 2020 del Juzgado de Instrucción n. 8 de Las Palmas de Gran Canaria.

Comisión de Derechos Humanos (1998a). Informe del Grupo de Trabajo sobre la Detención Arbitraria (E/CN.4/1999/63).

Comisión de Derechos Humanos (1998b). Informe del Grupo de Trabajo sobre la Detención Arbitraria - Adición (E/CN.4/1999/63/Add.3).

Comité de Derechos Humanos (2002). Dictamen sobre la comunicación n. 9090/1999 (CCPR/C/76/D/900/1999).

Comité de Derechos Humanos (2014). Observación general n. 35 (CCPR/C/GC/35).

Consejo de Derechos Humanos (2009). Informe del Grupo de Trabajo sobre la Detención Arbitraria (A/HRC/10/21).

Consejo de Derechos Humanos (2010). Informe del Grupo de Trabajo sobre la Detención Arbitraria (A/HRC/13/30).

Consejo de Derechos Humanos (2012). Informe del Relator Especial sobre los derechos humanos de los migrantes (A/HRC/20/24).

Consejo de Derechos Humanos (2013). Informe del Relator Especial sobre los derechos humanos de los migrantes (A/HRC/23/46).

Consejo de Derechos Humanos (2018a). Informe del Grupo de Trabajo sobre la Detención Arbitraria (A/HRC/39/45).

Consejo de Derechos Humanos (2018b). Grupo de Trabajo sobre la Detención Arbitraria: Revised Deliberation No. 5 on deprivation of liberty of migrants.

Consejo de Derechos Humanos (2020a). Informe del Grupo de Trabajo sobre la Detención Arbitraria (A/HRC/45/16).

Consejo de Derechos Humanos (2020b). Anejo explicativo de las observaciones de España a las recomendaciones recibidas por España con ocasión del tercer ciclo del Examen Periódico Universal.

Consejo de Europa (2017). Human Rights and Migration. Legal and practical aspects of effective alternatives to detention in the context of migration. Estrasburgo: Consejo de Europa.

Consejo de Europa (2019). Practical guidance on Alternatives to Immigration Detention: Fostering Effective Results. CDDH(2019)R91Addendum5.

European Asylum Support Office (2016). EASO guidance on reception conditions: operational standards and indicators.

European Migration Network (2014). The use of detention and alternatives to detention in the context of immigration policies. Synthesis report for the EMN Focused Study 2014.

Eurostat (2021a). First instance decisions on applications by citizenship, age and sex - annual aggregated data (rounded), MIGR_ASYDCFSTA. Última actualización: 3 de junio de 2021. Disponible en: https://bit.ly/2ThoN81. 
Eurostat (2021b). Third country nationals ordered to leave - annual data (rounded), MIGR_EIORD. Última actualización: 20 de mayo de 2021. Disponible en: https://bit.ly/3A37WH0.

Eurostat (2021c). Third country nationals returned following an order to leave - annual data (rounded), MIGR_EIRTN. Última actualización: 20 de mayo de 2021. Disponible en: https://bit.ly/3x1007a.

Gobierno de España (18 de enero de 2019). Mejora de las instalaciones de los Centros de Internamiento de Extranjeros (CIE) [web]. Disponible en: https://bit.ly/2UsTUOH.

Ley Orgánica 4/2000, de 11 de enero, sobre derechos y libertades de los extranjeros en España y su integración social.

Migraeurop (2013). Encierro de migrantes. El «modo de gestión» privilegiado de las migraciones. Boletín $n .^{\circ} 2$ de abril de 2013.

Ministerio de Inclusión, Seguridad Social y Migraciones (2021). Resolución de 27 de abril de 2021 de la Dirección General de Programas de Protección Internacional y Atención Humanitaria, por la que se convocan subvenciones para proyectos de retorno voluntario de persones nacionales de terceros países.

Parlamento Europeo (2020). Resolución de 17 de diciembre de 2020 sobre la aplicación de la Directiva sobre retorno (2019/2208(INI)).

Pueblos Unidos (2015). Situación actual de los centros de internamiento de extranjeros en España y su adecuación al marco legal vigente.

Sentencia del Tribunal Constitucional n. ${ }^{\circ}$ 115/1987, de 7 de julio.

Servicio Jesuita a Migrantes-España (2019). Informe CIE 2018: Discriminación de origen. Madrid: Servicio Jesuita a Migrantes.

Servicio Jesuita a Migrantes-España (2021). Informe CIE 2020: Razón jurídica y sinrazón política. Madrid: Servicio Jesuita a Migrantes. 